\title{
RETAINED PRIMITIVE REFLEXES AND ADHD IN CHILDREN
}

\author{
Jana Konicarova, ${ }^{1 *}$ Petr Bob ${ }^{2,3}$ \\ ${ }^{1}$ Department of Psychology, Faculty of Social Studies, Masaryk University, Brno, Czech Republic \\ ${ }^{2}$ Center for Neuropsychiatric Research of Traumatic Stress, Department of Psychiatry $\mathcal{E}$ \\ UHSL, $1^{\text {st }}$ Faculty of Medicine, Charles University, Prague, Czech Republic \\ ${ }^{3}$ Central European Institute of Technology, Faculty of Medicine, Masaryk University, Brno, \\ Czech Republic
}

\begin{abstract}
Particularly important postnatal developmental reflexes that diminish in later stages of development are Moro reflex and Galant reflex that belong among the so-called primitive reflexes. According to current evidence persistence of the primitive reflexes is related to certain specific neuropsychiatric disorders. According to current knowledge there is no evidence whether these reflexes play a role in Attention Deficit and Hyperactivity Disorder (ADHD). To develop these findings we have tested a hypothesis whether ADHD children in the school age (8-11 years) will have higher level of persisting primitive reflexes Moro and Galant compared to a control group of children of the same age. Results of this study show that ADHD children have high occurrence of primitive reflexes compared to the control group, which indicates that ADHD symptoms may present a compensation of unfinished developmental stages related to diminishing Moro and Galant reflexes.
\end{abstract}

Key words: ADHD; Galant Reflex; Moro Reflex; Developmental disorders; Primitive reflexes

\section{INTRODUCTION}

According to current evidence brain functions in their developmental stages are particularly vulnerable to postnatal developmental deficits that likely may have various etiological backgrounds (Teicher, Tomoda, \& Andersen, 2006; Fagiolini, Jensen, \& Champagne, 2009; Kolb \& Gibb, 2011) and may cause persisting of the so-called primitive reflexes (Allen \& Capute, 1986; Zafeiriou, 2004; Sanders \& Gillig, 2011).

Recent findings also indicate that persisting of the primitive reflexes may be linked to certain specific neuropsychiatric disorders (Keshavan \& Yeragani, 1987; Youssef \& Waddington, 1988; Zafeiriou, 2004; Links et al., 2010; Nicolson et al., 2011; Sanders \& Gillig, 2011) although according to current scientific findings there is no evidence whether these persisting reflexes play a role in Attention Deficit and Hyperactivity Disorder (ADHD). With respect to these missing findings (or at least very rare) we have proposed and tested the hypothesis to which extent ADHD will be related to persisting Moro and Galant reflexes in children in the school age (8-11 years) compared to a control group of children of the same age.

${ }^{*}$ Correspondence to: Jana Konicarova, e-mail: jana.konicarova@seznam.cz

Received September 26, 2012; accepted October 28, 2012; Act Nerv Super (Praha) 54(3-4), 135-138. 


\section{METHODS}

\subsection{Participants}

Within the framework of ELSPAC (European Longitudinal Study of Parenthood and Childhood) study data of 20 children (8-11 year old, 10 girls and 10 boys) with ADHD diagnosed according to DSM-IV criteria and 20 healthy children (8-11 year old, 10 girls and 10 boys) characterizing their primary reflex responses were collected. Parents of all the participants gave written informed consent and the ELSPAC study was approved by Masaryk University, Faculty of Medicine ethical committee.

\subsection{Measurement of primitive reflexes}

\subsubsection{Moro Reflex or Erect Test for Vestibular-activated Moro (Goddard, 2005).}

Test Position: The subject stands with feet together, the arms and body form a 45-degree angle with the hands flexed at the wrists.

Test Procedure: The tester stands behind the subject and instructs the child to bend its head back as if looking at the ceiling and close its eyes. Note any arm movement or loss of balance as a result of putting the head into extension. Once the subject has stabilized in this position, give the instruction to remain still and fall backwards at a given sound. The tester must be prepared to catch the full weight of subject.

Observations: The abduction of arms, falling back and/or an intake of breath or a cry as it loses the centre of balance. A notable reddening of skin or pallor, tremor and withdrawal immediately after testing.

Scoring: 0 - subject falls back with no alteration of arm position; 1 - a reddening of skin or slight but quick controlled movements of arms or hands outwards, inability to drop back, a movement of the arms and hands outwards, dislike of procedure; 2 - a movement of arms accompanied by "freezing" momentarily in this position, a gasp of breath, a reddening of skin or pallor, a complete abduction of arms and hands outwards accompanied by gasp, freeze and possible cry or a visible dislike or distress (Goddard, 2005).

\subsubsection{Spinal Galant Reflex (Goddard, 2005).}

Test position: Four point kneeling or "table" position

Test procedure: Using a light brush, stroke down the back from below the shoulder to the base of the lumbar region at a distance of $1 / 2$ inch from the spine, first on one side, then on the other. Repeat the procedure up to 3 times (repetition beyond this can fail to elicit the reaction even though the reflex is present).

Observations: Movement of the hip outwards in response to stimulation.

Scoring: 0 - no response; 1 - undulation or movement of the hip outwards to $30^{\circ} ; 2$ undulation or movement of the hip outwards to $45^{\circ}$, movement outwards, beyond $45^{\circ}$ and may affect the child's balance, hypersensitivity, ticklishness, may also be present.

\section{STATISTICAL ANALYSIS}

Statistical evaluation of scores of the measures of primitive reflexes in ADHD and the control group included descriptive statistics and Mann-Whitney tests for independent samples.

All the methods of statistical evaluation were performed using the software package Statistica Version 6. 


\section{RESULTS}

Results of the analysis show that the ADHD participants have higher ratings of primitive reflexes i.e. Moro reflex and Galant reflex in comparison to healthy participants who had lower scores of the primitive reflexes (Table 1) and also descriptive statistics shows high differences between the ADHD and control group of participants. Statistically significant differences between boys and girls were not found.

Table 1. Statistical comparison of scores related to neonates reflexes in ADHD children in comparison to the control group of healthy children using Mann-Whitney test.

\begin{tabular}{|c|c|c|c|c|c|c|c|}
\hline & \multicolumn{2}{|l|}{$\begin{array}{l}\text { ADHD } \\
(\mathrm{N}=20)\end{array}$} & \multicolumn{2}{|c|}{$\begin{array}{l}\text { Controls } \\
(\mathrm{N}=20)\end{array}$} & \multirow[b]{2}{*}{$U$} & \multirow[b]{2}{*}{$\begin{array}{c}\text { Adjust. } \\
\text { Z }\end{array}$} & \multirow[b]{2}{*}{$\begin{array}{c}\text { Adjust. } \\
p\end{array}$} \\
\hline & Mean & $S D$ & Mean & $S D$ & & & \\
\hline Moro & 0.85 & 0.81 & 0.05 & 0.22 & 87.5 & 3.68 & 0.0002 \\
\hline Galant & 0.70 & 0.92 & 0.10 & 0.44 & 131 & 2.56 & 0.0103 \\
\hline
\end{tabular}

\section{DISCUSSION}

Results of this study support the hypothesis that ADHD diagnosis is closely linked to persisting primitive Moro and Galant reflexes in children in the school age. These persisting developmental stages related to certain motor and cognitive functions may indicate that ADHD present a compensation of unfinished developmental stages related to diminishing of primitive reflexes that may occur as a response to various stimuli. These changes possibly may explain ADHD symptoms as consequence of a conflict between higher and lower levels of cognitive and motor functions during brain processing. This finding in ADHD patients is in agreement with few reported studies in patients with dyslexia documenting higher level of persisting primitive reflexes (McPhillips, Hepper, \& Mulhern, 2000; McPhillips \& JordanBlack, 2007).

As a consequence, these persisting primitive reflexes may play a role in ADHD. In the light of current findings these data are in agreement with neurological concept proposed by Jacksonian theory according to which persisting primitive reflexes may cause "dissolution" (Andermann, 1997; Franz \& Gillett, 2011; Jacyna, 2011) that may result in ADHD patients into various symptomatic forms (Endo, Sugiyama, \& Someya, 2006; Johnson et al., 2007). This process of dissolution related to retained primitive reflexes is based on disinhibition of neural functions or their release from control that leads to dysregulation of later developed adaptive functions (Franz \& Gillett, 2011) and may be linked to various neuropsychiatric syndromes (Keshavan \& Yeragani, 1987; Youssef \& Waddington, 1988; Zafeiriou, 2004; Links et al., 2010; Nicolson et al., 2011; Sanders \& Gillig, 2011).

\section{ACKNOWLEDGEMENT}

The study was supported by the grant GACR P407/12/1957, project MSM0021620849 provided by Czech Ministry of education and the project "CEITEC - Central European 
Institute of Technology" (CZ.1.05/1.1.00/02.0068) from European Regional Development Fund.

\section{REFERENCES}

Allen, M. C., Capute A. J. (1986). The evolution of primitive reflexes in extremely premature infants. Pediatric Research, 20, 1284-9.

Endo, T., Sugiyama, T., \& Someya, T. (2006). Attention-deficit/hyperactivity disorder and dissociative disorder among abused children. Psychiatry and Clinical Neurosciences, 60, 434-8.

Fagiolini, M., Jensen, C.L., \& Champagne, F.A. (2009). Epigenetic influences on brain development and plasticity. Current Opinion in Neurobiology, 19, 207-12.

Franz, E. A., \& Gillett, G. (2011). John Hughlings Jackson's evolutionary neurology: a unifying framework for cognitive neuroscience. Brain, 134, 3114-20.

Goddard, S. (2005) Reflexes, learning and behavior: A window into the child's mind. Eugene, OR: Fern Ridge Press.

Jacyna, L. S. (2011). Process and progress: John Hughlings Jackson's philosophy of science. Brain, 134, 3121-6.

Johnson, K. A., Robertson, I. H., Kelly, S. P., Silk, T. J., Barry, E., Dáibhis, A., Watchorn, A., Keavey, M., Fitzgerald, M., Gallagher, L., Gill, M., \& Bellgrove, M.A. (2007). Dissociation in performance of children with ADHD and high-functioning autism on a task of sustained attention. Neuropsychologia, 45, 2234-45.

Keshavan, M. S., \& Yeragani, V. K. (1987). Primitive reflexes in psychiatry. Lancet, 1, 1264.

Kolb, B., \& Gibb, R. (2011) Brain plasticity and behaviour in the developing brain. Journal of the Canadian Academy of Child and Adolescent Psychiatry, 20, 265-76.

Links, K. A., Merims, D., Binns, M. A., Freedman, M., \& Chow, T.W. (2010). Prevalence of primitivereflexes and Parkinsonian signs in dementia. Canadian Journal of Neurological Sciences, 37, 601-7.

McPhillips, M., Hepper, P. G., \& Mulhern, G. (2000). Effects of replicating primary-reflex movements on specific reading difficulties in children: a randomised, double-blind, controlled trial. Lancet, 355, 537-541.

McPhillips, M., \& Jordan-Black, J. A. (2007). Primary reflex persistence in children with reading difficulties (dyslexia): A cross-sectional study. Neuropsychologia, 45, 748-754.

Nicolson, S. E., Chabon, B., Larsen, K. A., Kelly, S.E., Potter, A. W., \& Stern, T. A. (2011). Primitive reflexes associated with delirium: a prospective trial. Psychosomatics, 52, 507-12.

Sanders, R. D., \& Gillig, P. M. (2011). Reflexes in psychiatry. Innovations in Clinical Neuroscience, 8, $24-9$.

Teicher, M. H., Tomoda, A., \& Andersen, S. L. (2006). Neurobiological consequences of early stress and childhood maltreatment: are results from human and animal studies comparable? Annals of the New York Academy of Sciences, 1071, 313-323.

Youssef, H. A., \& Waddington, J. L. (1988). Primitive (developmental) reflexes and diffuse cerebral dysfunction in schizophrenia and bipolar affective disorder: overrepresentation in patients with tardive dyskinesia. Biological Psychiatry, 23, 791-6.

Zafeiriou, D. I. (2004). Primitive reflexes and postural reactions in the neurodevelopmental examination. Pediatric Neurology, 31, 1-8. 